AUTHOR:

Dr M. Pienaar ${ }^{1}$

Dr E. Mostert ${ }^{1}$

AFFILIATION:

${ }^{1}$ University of Pretoria,

South Africa

DOI: http://dx.doi. org/10.18820/2519593X/pie.v39.

i1.27

e-ISSN 2519-593X

Perspectives in Education

$202139(1): 442-470$

PUBLISHED:

12 March 2021

RECEIVED:

9 November 2020

ACCEPTED:

20 January 2021

\section{THE TEACHING MIX MATTERS: RETHINKING VETERINARY EDUCATION AT A SOUTH AFRICAN UNIVERSITY}

\begin{abstract}
Globally, the COVID-19 pandemic necessitated a shift in teaching and learning practices. The University of Pretoria in South Africa was not entirely unprepared for this event, since the university's teaching strategy had gradually evolved into a hybrid delivery mode. In the Faculty of Veterinary Science, however, the practical nature of the discipline brought about unique challenges in implementing hybrid-mode teaching and learning methodologies. An intervention was thus required to empower lecturers in the faculty to adapt their teaching methodologies to incorporate the hybrid teaching and learning mode. The aforementioned intervention was gleaned from a professional development framework developed by Brown et al. (2010) with a definite focus on core knowledge, areas of activity and core values. Long before the COVID-19 pandemic, the university's educational support department developed and presented a tailor-made course, called "The Mix Matters: Step up your hybrid teaching", to enhance lecturers' hybrid teaching skills. Unknowingly, the workshop amply prepared the lecturers for what was still to come in 2020. The aim was to provide participants with a deep understanding of the complexities involved and the skills required for revising and quality-assuring academic courses for the hybrid-teaching environment. Using a mixed-method research design, this paper elucidates how the training and its learning outcomes inspired the lecturers to implement the hybrid teaching and learning mode that conforms to the University of Pretoria's teaching and learning model. A noticeable paradigm shift was accomplished once the initial scepticism had turned into enthusiasm and positive attitudes.
\end{abstract}

Keywords: Hybrid learning; academic development; professional development; technology-enhanced learning; inquiry-based learning; COVID-19.

\section{BACKGROUND AND OBJECTIVES}

The Faculty of Veterinary Science (henceforth the faculty) at the University of Pretoria in South Africa (UP) faces unique challenges with regard to teaching and learning methodologies. It has to implement the hybrid delivery mode that UP has adopted as its preferred teaching strategy, thereby including sophisticated educational technology as a pivotal part of its teaching and learning strategy (cf. Hybrid teaching and learning in context). Owing to the nature of 
veterinary training, the implementation of appropriate educational technology, open education resources (OER) and applicable electronic resources calls for innovative teaching and learning practices (cf. Hybrid teaching and learning in context). The faculty has to accommodate the growing number of student intake in the Bachelor of Veterinary Science (BVSc) and the Diploma Veterinary Nursing (DVN) (now the Bachelor of Veterinary Nursing (BVetNurs)) programmes while simultaneously embracing the inclusion of educational technology as a pivotal part of its teaching and learning strategy.

The implementation of the hybrid teaching and learning mode falls within the realm of faculty development, which has emerged as an important field of practice that includes staff, academic and educational development (Warman, Pritchard \& Baillie, 2015) (cf. Hybrid teaching and learning in context). The Department for Education Innovation (EI) plays an integral part across the university in preparing lecturers for this mode of teaching. El is mainly responsible for the academic development of lecturers in all faculties; and to accomplish this, each faculty has an educational consultant (EC) and an instructional designer (ID). When the Veterinary School at the University of Bristol implemented a new curriculum, Warman et al. (2015) investigated the academic development of staff and made a number of important findings. Firstly, implementing academic development strategies improved teaching performance and staff morale. Secondly, switching from a teacher-led to a student-centred teaching and learning approach improved students' learning experiences, thus making it essential, although (owing to the practical nature of the discipline) veterinary science education had never been associated with the extensive use of educational technology combined with a student-centred teaching and learning approach. Thirdly, lecturers' educational technology skills had to be enhanced to enable them to incorporate the hybrid teaching and learning mode as a method of teaching. El staff in UP's veterinary science faculty therefore designed a workshop, "The Mix Matters: Step up your hybrid teaching" (the workshop), for this purpose. Unknowingly this workshop prepared the lecturers in this faculty to perform optimally during the COVID-19 pandemic.

The workshop fits into the bigger context of the UP teaching model and UP's teaching and learning approach, which endeavours to equip UP graduates with attributes such as critical thinking skills, innovation, ethical reasoning and digital fluency skills (to name but a few) - skills essential for participation in the Fourth Industrial Revolution (4IR). The hybrid approach plays an essential role in developing these qualities in the UP students (Department for Education Innovation, 2020). The UP teaching and learning approach is also based on inquiry-based learning (IBL) and community-based learning. IBL results in deep, active learning (cf. Hybrid teaching and learning in context). Students control how they develop their knowledge base through cognitive engagement that requires the application of higher-order thinking skills (Cleveland-Innes \& Wilton, 2018).

The hybrid teaching and learning mode extends the classroom experience before and after class, in accordance with the three phases of the UP model, namely students' preparation before class, their engagement during class and the consolidation phase after class (Department for Education Innovation, 2020) (cf. Hybrid teaching and learning in context). Hybrid teaching allows lecturers to mix the best of contact and online delivery, and to shift the instructional sequence in ways that create a new learning environment for their students, thereby making teaching and learning more effective (Department for Education Innovation, 2019). The intended outcome is improved student success and lower student retention, which supports UP's campaign The Finish Line is Yours (FLY@UP) that encourages 
students to finish their studies within the minimum time. One of the slogans that promote the FLY@UP campaign is “The learning mix matters", which focuses students' attention on the hybrid teaching and learning mode. The same phrase and emphasis appear in the workshop designed to entice and persuade veterinary science lecturers to use this mode of teaching by enhancing their hybrid teaching skills and emphasising that the teaching mix is important. As Rapanta et al. (2020) and Mohamedbhai (2020) emphasise, online learning is not merely adding notes and study material or recorded lectures to an online platform, and thus it requires that lecturers be trained in the pedagogy of delivering online teaching.

Although this model was developed prior to any indication of an impending global pandemic, it created an avenue by which lecturers could continue their teaching activities with minimal disruption as universities globally shut down their campuses and suspended contact academic activities to prevent transmission of the COVID-19 virus. Some months after having temporarily halted academic programmes, it became clear that the pandemic would last for some time to come. Its effect on higher education would remain for many years and all institutions of higher education should be prepared to address the consequences (Mohamedbhai, 2020). South Africa's largest universities responded by migrating to online teaching. Since most had already implemented some learning management system (LMS), most lecturers made the transition fairly smoothly. ${ }^{1}$ This was confirmed by Professor Mamokgethi Phakeng, vice-chancellor (VC) of the University of Cape Town (UCT), who stated that online teaching had been used at UCT for some time already (Opinion, 2020). Professors Tawana Kupe and Adam Habib, VCs of UP and the University of the Witwatersrand (Wits) respectively, both indicated that the blended (at UP, the hybrid) mode of teaching would remain and a higher-education environment consisting of only face-to-face teaching would no longer be viable. They concurred that the influence of COVID-19 on higher-education institutions would be global and would include a revised teaching approach (Opinion, 2020).

Kupe rightly emphasised that training the lecturers increases the success of hybrid teaching (Opinion, 2020). The implementation of a blended or hybrid model is challenging for lecturers and students (Vaughan, 2007) since lecturers require support to redesign their courses to fit this mode of delivery. Aiming to address this challenge, the workshop observed four main objectives:

- to provide participants with a deep understanding of the complexities of revising and quality-assuring academic courses;

- to teach participants the skills needed for planning, designing and quality-assuring new courseware using a set of different teaching and learning methodologies, including IBL;

- to have each participant compile detailed course plans and an assessment plan to take away from the workshop; and

- to have each participant develop some electronic resources that would enhance the flipped classroom approach in a hybrid teaching and learning mode (cf. Hybrid teaching and learning in context).

A professional development framework developed by Brown et al. (2010), with the focus on the following domains: core knowledge, areas of activity and core values forms the theoretical framework and objective of this paper. This paper will highlight the kind of training El provided

1 Sadly, many students had problems transitioning to the "online only" environment, inter alia owing to limited access to electronic devices and to the Internet. Attempts were made to assist students, but this topic warrants a separate discussion. 
to empower lecturers to change their teaching practices to incorporate the hybrid teaching and learning mode based on this framework. It will also reveal the research undertaken by El staff to find, and to teach lecturers applications or working solutions that would enable them to teach "smarter" in order to enhance the quality of learning in a hybrid teaching and learning mode. In our faculty, the workshop had serendipitously prepared UP lecturers well for online teaching, during the COVID-19 pandemic and beyond.

\section{HYBRID TEACHING AND LEARNING IN CONTEXT}

The literature contains a plethora of definitions that describe online learning in its many different varieties, making it nearly impossible to provide a definitive definition for online learning in the context of hybrid teaching and learning. Online learning is just a mode of delivery. In its simplest manifestation, it is any form of learning conducted (partly or entirely) over the Internet. A computer or any other type of device that can connect to the Internet would be required to access all or some information and for collaboration between students and lecturers (Bates, 2016). Online learning supports a number of teaching methods in a continuum, as depicted in Figure 1 below (Bates, 2016).

\section{blended}

\section{face-to-face | classroom aids | flipped | hybrid | fully online (distance)}

\section{no technology}

(delivery)

all technology

Figure 1: Teaching continuum (Bates, 2016)

Modern teaching and learning covers a broad spectrum of methodologies and activities, as shown in Figure 1. Blended teaching and learning occurs when some forms of technology are utilised as classroom and teaching aids, which could include online learning, thus making blended learning a sub-branch of online learning (Bates, 2016). Figure 1 also shows that technology-enabled learning is an important component of blended learning.

Technology-enabled learning is the application of digital technology to teaching and learning in an educational context (Kirkwood \& Price, 2016). The intention of technologyenabled teaching and learning is for learning to result from the lecturers' and students' interaction with the technology (Kirkwood \& Price, 2016). It furthermore suggests that educational technology can enhance teaching and learning. Although there are no explicit statements in the literature that can vouch for the aforesaid enhancements, the researchers are of the opinion that technology-enhanced teaching and learning could positively impact the effectiveness of hybrid teaching and learning (cf. The workshop; Analysis and interpretation of questionnaires - Day 2, Day 4). It is also obvious that in blended learning, face-to-face teaching and learning is combined with some online learning, making it a web-enhanced teaching and learning approach (Vernadakis et al., 2011). "This mix [which has a defined UP standard as to how many courses go online] is influenced by many factors, including the course outcomes, student characteristics, lecturer's experience and teaching style, discipline, developmental level, and online resources" (Dziuban, Moskal \& Hartman, 2004). At UP, in basic terms, a course is considered mainly face-to-face when the online component is about 
$30 \%$ and the face-to-face-component about $70 \%$. Conversely, a fully online course has an online component of about $70 \%$ and a face-to-face contact component of about $30 \%$. The hybrid is the various mixes available and possible within the aforementioned parameters. In UP's hybrid teaching and learning mode, Internet resources and UP's Blackboard Learn ${ }^{\mathrm{TM}}$ learning management system (LMS), branded as clickUP, offer students and lecturers easier access to learning content through the use of various tools available to them. The LMS and Internet resources also allow access to material and to experts who might not have been available otherwise, resulting in a learning environment where students are being actively engaged and are potentially learning more than they would have if a traditional linear teaching model had been used (cf. The workshop).

The literature reveals that, often, the terms "blended learning" and "hybrid learning" are used interchangeably. Although both approaches combine lecturer-led classes with online instruction, the literature does show a subtle difference between blended and hybrid learning. Blended learning goes beyond e-learning (Steffens \& Reiss, 2010); it is not achieved by merely adding educational technology to a course. Blended learning requires an integrated plan of student-centred classroom instruction and online learning that is collaborative, accessible, can be personalised (Cleveland-Innes \& Wilton, 2018) and it is a continuous process (Vernadakis et al., 2011). Hybrid learning focuses on the most effective way to deliver a course to a student in an interactive and engaging manner, ensuring qualitatively better interaction between student and lecturer and between peers (MicroTek, 2017) (cf. Analysis and interpretation of questionnaires - Day 1; Post-workshop survey).

The combination described above would normally manifest as a flipped classroom approach in a hybrid teaching and learning mode (cf. Discussion). This approach requires that students prepare for their face-to-face sessions online and outside the classroom and these preparations usually entail a number of activities (Bates, 2016). Doing so saves teaching time and allows for more student-centred activities that would encourage deep learning. Hybrid learning requires a total redesign of the face-to-face classroom experience, where students spend $50 \%$ or more of their time online and the lecturer determines the most effective ways of utilising online and face-to-face activities (Bates, 2016). The emphasis on active learning and a reduction of classroom time in the blended learning model is known as hybridisation, which "mixes" the online component and the face-to-face components, creating an environment highly conducive to student learning (Vaughan, 2007) (cf. Hybrid teaching and learning in context). Hybrid courses furthermore utilise significant e-learning activities in addition to traditional classroom face-to-face teaching and learning (Vernadakis et al., 2011).

The UP teaching and learning model requires that students prepare before they attend classes (or synchronous online learning activities), as this enables the new teaching to build actively on their prior knowledge. A plethora of technological developments can prepare students and make learning active and meaningful - these proved extremely useful during the COVID-19 pandemic. An inquiry-based approach to teaching and learning is advocated, because research shows that inquiry-based learning motivates students, stimulates critical thinking, and creates opportunities for developing a deeper understanding of concepts. The research also emphasises the importance of explaining: "The learning strategies for which there is evidence of effectiveness include ways to help students retrieve information and encourage them to summarize and explain material they are learning" (National Academies of Sciences, Engineering, and Medicine, 2018:106). The final phase of the flipped classroom approach is where consolidation takes place after class. Assignments after class provide further 
opportunity to consolidate students' knowledge and organise it into meaningful hierarchical patterns. This mastery of concepts facilitates the transfer of learning and allows students to use their knowledge and distributed resources to solve problems. The above described UP teaching model is depicted in Figure 2 below (Department for Education Innovation, 2020) (cf. The workshop).

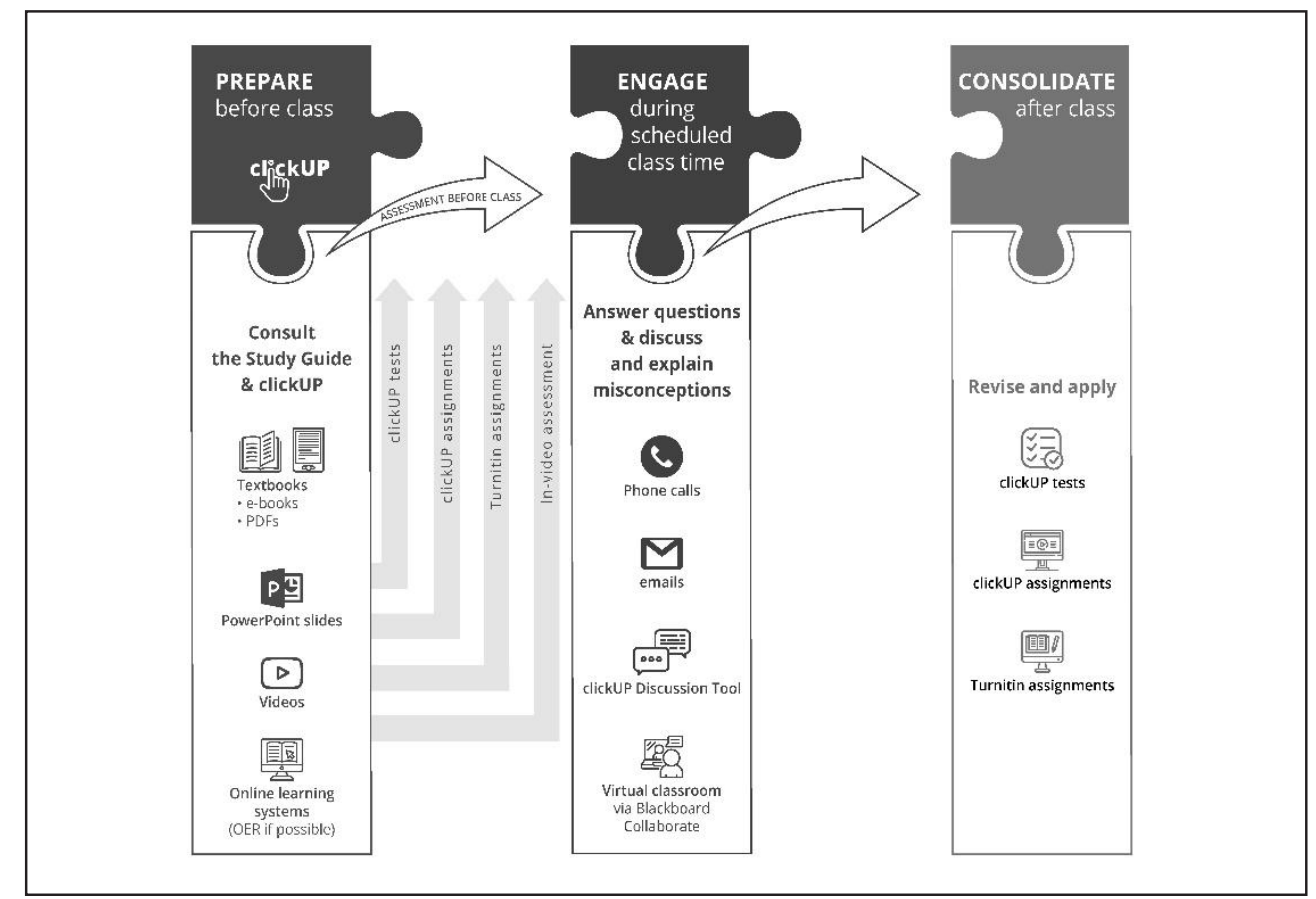

Figure 2: UP teaching and learning model (Department for Education Innovation, 2020)

UP's teaching and learning approach is based on IBL, hybrid learning and communitybased learning (cf. Analysis and interpretation of questionnaires - Day 1). The university adopted this approach primarily because it believes that, pedagogically, its benefits (see pp. 2-3) outweigh those of the traditional (only) face-to-face teaching mode. (In addition, it also proved its advantage under lockdown circumstances.) However, it is important to note that hybrid teaching and learning activities should best suit the course, the students' needs and the curriculum requirements, making it a student-centred approach that is accessible and where the focus is on pedagogy, not technology. For this reason, UP favours a mix of blended in-person, blended online, flipped and technology-enabled classes that integrate a range of higher-order learning opportunities for deep and meaningful learning.

In the Faculty of Veterinary Science, the aforementioned approaches to hybrid teaching and learning at UP was associated with specific challenges. The first challenge - time, access and awareness (Warman et al., 2015) - manifested in various ways. Academic staff found it difficult to fulfil all of the duties (academic, clinical and research) expected of them and COVID-19 only aggravated the situation (Rapanta et al., 2020). A lack of access to technology also emerged as a problem: not owning a device (mostly students) and/or occasionally unreliable Internet connectivity. Since teaching activities had to continue during lockdown, UP supplied devices and (free) data where possible, but the situation made it difficult for 
lecturers to choose teaching and learning activities with the available technology in ways that would allow all students to participate in an engaged manner. Some lecturers and students lacked the technological skills and competence required for using and applying technology in innovative ways. From a lack of awareness, lecturers sometimes neither focused on the proper use of educational technologies, nor provided experience with online coursework from a student perspective. A lack of skills to meaningfully engage with learning modalities also negatively affected lecturers and students' motivation. Huge workloads, also in hybrid sections of courses, had the same demotivating effect. In some courses, weak online components were another concern raised. The pandemic forced academics to suddenly take on the additional role of instructional designer in order to continue their teaching activities successfully (Rapanta et al., 2020).

The second challenge is that of motivation and resistance to change (Warman et al., 2015). To succeed in bringing about change there must be a personal desire to change, knowledge regarding how to change, a supportive environment and rewards for changes made. Not all lecturers were positive about the hybrid teaching and learning modality and not all felt equipped to drastically change their teaching. Providing some training and assistance (as per the workshop) was therefore crucial for hybrid teaching and learning to succeed. (COVID-19 eventually swayed those who still resisted change.)

The third challenge is relevance, recognition and reward (Warman et al., 2015). It was important to ensure that the workshop was relevant and addressed the lecturers' needs. The feedback at the end of each day was therefore crucial to determine how relevant the lecturers had found it (cf. Data capturing and analysis). The fourth challenge is the evaluation of programme success (Warman et al., 2015) (cf. Post-workshop survey). Ongoing research is required to gauge the impact of the workshop on the success rates of the two undergraduate programmes.

The workshop emphasised two of the pedagogical principles (i.e. theories that govern good educational practice) that are essential for veterinary education, namely active learning (cf. Hybrid teaching and learning in context), and valid and reliable assessment (May \& SilvaFletcher, 2015) (cf. Analysis and interpretation of questionnaires - Day 3). A third pedagogical principle, moving away from lecturer-centred learning to a model of student-centred active learning, was entrenched as one of the goals of the workshop (cf. Background and objectives; The workshop). Fourthly, the use of technology is the preferred platform in a hybrid model (May \& Silva-Fletcher, 2015), but even though "e-learning technology developed around the hybrid paradigm is beneficial for improving the quality of learning, [it] is useless if it is not based on pedagogical prescriptions" (Vernadakis et al., 2011:189).

\section{RESEARCH METHOD}

\subsection{Research design}

The research is vested in the pragmatic research paradigm that allowed the researchers to use multiple research methods and different forms of data collection and analysis (Creswell, 2009). The researchers were concerned with applications or working solutions to enable smarter teaching in the faculty's hybrid teaching and learning approach that aligns with the university's teaching and learning model. Combined qualitative and quantitative research designs (mixed-methods research) were used to collect and analyse textual and numerical 
data. Subsequently, the research results were used to inform the way the hybrid model of teaching and learning was implemented in the faculty.

\subsection{Literature review}

The researchers consulted international and national primary and secondary sources to obtain information for addressing the purpose of the study. Published articles, books and official documents that are relevant to the field of study were studied (cf. Hybrid teaching and learning in context).

\subsection{Research process and ethical considerations}

The population for this research comprised the lecturing staff in the faculty. The sample group comprised those lecturers and library staff who were directly involved in teaching the BVSc and DVN (now the BVetNurs) programmes $(n=37)$ during 2017 and 2018. The researchers applied target sampling to select potential research participants, focusing on a specific group of lecturing staff members. In 2019, the participants were surveyed to determine to what extent they had implemented the training received in the workshop.

The researchers were granted ethical clearance by UP's Research Ethics Committee in the Faculty of Humanities (GW20180731HS). The researchers also obtained informed consent from the Deputy Dean: Teaching and Learning of the Faculty of Veterinary Science and from the participants. Confidentiality and anonymity were observed. Participation was voluntary, and participating staff members were informed that they could withdraw from the study at any time without any consequences to them.

\subsection{Data capturing and analysis}

The research was based on sound data and findings obtained from the study in a scientific manner. Qualitative data and quantitative data were collected through self-generated online questionnaires. The researchers argued that the questionnaires were appropriate for gathering data since it would elicit relevant information on the effectiveness and the success of the workshop. The questionnaires were created in Qualtrics ${ }^{\mathrm{XM}}$, UP's official online survey software. The questions included a variation of closed and open-ended question types to generate useful information (Maree \& Pietersen, 2007) about the level of success of the workshop in terms of the implementation of hybrid teaching and learning. Upon completion of the questionnaires, the participants submitted their responses to the Qualtrics ${ }^{\mathrm{XM}}$ server. $^{-}$

Data that could inform the effectiveness of the workshop were collected. In the course of the workshop, participants were given opportunities to provide feedback on each day's presentations and activities. The feedback focused on the participants' level of satisfaction with the applicability and the presentation of the topics. The participants also shared what they had, and had not, enjoyed. To avoid preconceptions, assumptions and biases, the researchers continually observed dependability, reliability, credibility and conformability. The researchers followed the guidelines proposed by Shenton (2004) and addressed dependability by reporting in detail the processes within the study. The reporting of the processes would ensure that if future researchers repeat the study, and not necessarily gain the same result, the research will still be reliable. Credibility was provided by instilling honesty in the participants when contributing data. The participants were also allowed to refuse to participate in the research to ensure that the data collection involved only those willing to participate and offer their feedback. Furthermore, short, daily debriefing sessions of each day's sessions during the 
workshop also ensured credibility. Through the debriefing sessions, the researchers were able to test their interpretations and recognise their biases. Conformability was confirmed by only reporting the experiences of the participants in the findings of the study.

\subsection{The workshop}

Despite the practical nature of the veterinary discipline, the faculty adhered to UP's decision to change its teaching strategy to a hybrid delivery mode and thus switched to a hybrid teaching and learning mode. The student-centred teaching and learning strategies implemented had to be innovative, considering the specific nature of the discipline. El had to empower lecturers to enhance their teaching and educational technology skills for this purpose. The researchers therefore designed and developed the workshop with this in mind.

The rationale behind the workshop was to support the academic staff members in revising their course materials to:

- develop courses that support hybrid teaching and learning;

- embrace technology;

- implement the UP teaching model; and

- use a set of different teaching and learning methodologies, including IBL (cf. Hybrid teaching and learning in context).

The aim was to guide the participants to develop a deep understanding of the complexities involved and the skills required for revising and quality-assuring academic courses for the hybrid teaching environment. The workshop provided participants with some of the skills required to plan, design and quality-assure new courseware by using a set of different teaching and learning methodologies, including IBL (as stated above under the rationale). At the conclusion of the workshop, the participants would also have been encouraged to adopt the flipped classroom approach in a hybrid teaching and learning mode (cf. Hybrid teaching and learning in context).

The workshop programme contained strategically selected topics that the researchers presented using the hybrid mode of delivery. These topics included:

- The core principles that need to shape the revision of the courses to support hybrid teaching and learning. This topic focused on hybrid teaching and learning characteristics, the integration of information communication technology (ICT) into the lesson design, e-learning, a brief overview of the use and development of OER, IBL lesson design and student-centric methodologies.

- The latest learning theories. This topic offered an outline of how today's youth have developed different ways of learning. It also included suggestions for how lecturers should design their teaching and learning environment to support the students' learning preferences.

- A definite focus on how to ensure alignment of the outcomes indicated in the curriculum documents with the needs of an existing module. Curriculum critique was also encouraged.

- Existing course analysis. Participants were provided with an interactive course evaluation tool and asked to analyse an existing course. The tool queries course length, course content size, relevance and currency of the content, opportunities for student practise, opportunities for interacting with external experts, pedagogical approaches, use of technology, opportunities for "anywhere, anytime learning", etc. 
- Hybrid and blended learning. The researchers exposed the participants to exemplary use of UP's LMS to create learning environments that use e-learning and face-to-face sessions optimally.

- LMS functionalities. Participants identified those LMS tools that they could utilise most effectively.

- Developing a learning pathway. Participants were guided how to develop a learning pathway that would guide students through the blended learning experience. Where necessary and applicable, the sequence of learning events was clearly shown.

- Alternative pedagogies. Participants interrogated examples of IBL and had to consider how they might use the same approaches for at least one subtopic of their new design. Participants also had to consider how it would affect their assessment strategies.

- Assessment strategies. The researchers exposed the participants to accountable assessment by discussing the context in which assessment takes place as well as the educational impact of assessment. Participants were given the task of developing an assessment plan for their modules that would also indicate to what extent it aligns with the module outcomes and teaching methods, taking into account Biggs' constructive alignment model (Biggs, 2003). Various types of assessment tasks and tools (including e-assessment tools) were discussed as well as how to implement assessment in a hybrid model.

- Assessment planning document. Participants planned their assessment tasks in group activities and ascertained to what extent they would align with the module outcomes and teaching methods.

- Exposure to OER and Creative Commons licensing.

- Creating digital resources. Participants were encouraged to create their own digital resources, such as videos and narrated PowerPoint presentation slide decks.

The participants had access to a vast array of resources they could utilise. The resources included ICT and educational technology tools, including Office Mix, TurningPoint clicker technology, Turnitin (to be used as a tool for improving students' writing) and video-editing software.

\section{RESULTS AND DISCUSSION}

The data was obtained through self-developed online questionnaires and were analysed and interpreted in order to determine the value of the workshop in terms of explicating the skills required for implementing the hybrid mode of teaching. Out of a possible 37 participants $(n=37)$, 29 participants $(78 \%)$ completed the online questionnaires regarding their experiences of the workshop. Participants were also requested to complete a follow-up questionnaire to obtain information on the implementation of the hybrid model in their teaching practice and $14(38 \%)$ participants completed the latter questionnaire. The analysis and interpretation of the data obtained are presented below as per each section of the questionnaires. The researchers analysed the data obtained by using a descriptive approach in the form of frequencies, percentages and graphical techniques.

Feedback was obtained from the participants on their level of satisfaction about the applicability and the presentation of the topics. The participants were also offered the opportunity to share the things they enjoyed and did not enjoy each day. In addition, they could also make suggestions for improvements to any aspect of the workshop sessions. 


\subsection{Analysis and interpretation of questionnaires}

The workshop was presented several times in 2017 and 2018, and based on participants' feedback (in both the questionnaire and in discussions), some changes were made to the chronological presentation and the content of the various topics. The instruments are available in Appendices A to D.

\section{Day 1}

The following main topics were addressed on Day 1 :

- Developing a learning pathway

- IBL and the hybrid teaching and learning approach

- Latest learning theories

- Existing course analysis

- Using a planning template

The results of Day 1 of the first workshop are presented in Figure 3. It can be summarised as follows: Of the 29 participants who completed the questionnaire, $14(48 \%)$ were satisfied to some extent, and $15(52 \%)$ were very satisfied with the applicability of the session on the hybrid teaching and learning approach. Concerning the latest theories of learning, $16(55 \%)$ of the participants were satisfied, whereas $13(45 \%)$ were very satisfied. Twenty-seven participants $(93 \%)$ were satisfied to very satisfied with the applicability of the planning template and the existing course analysis activity. The participants appreciated the opportunity to work with the template and analyse their existing courses.

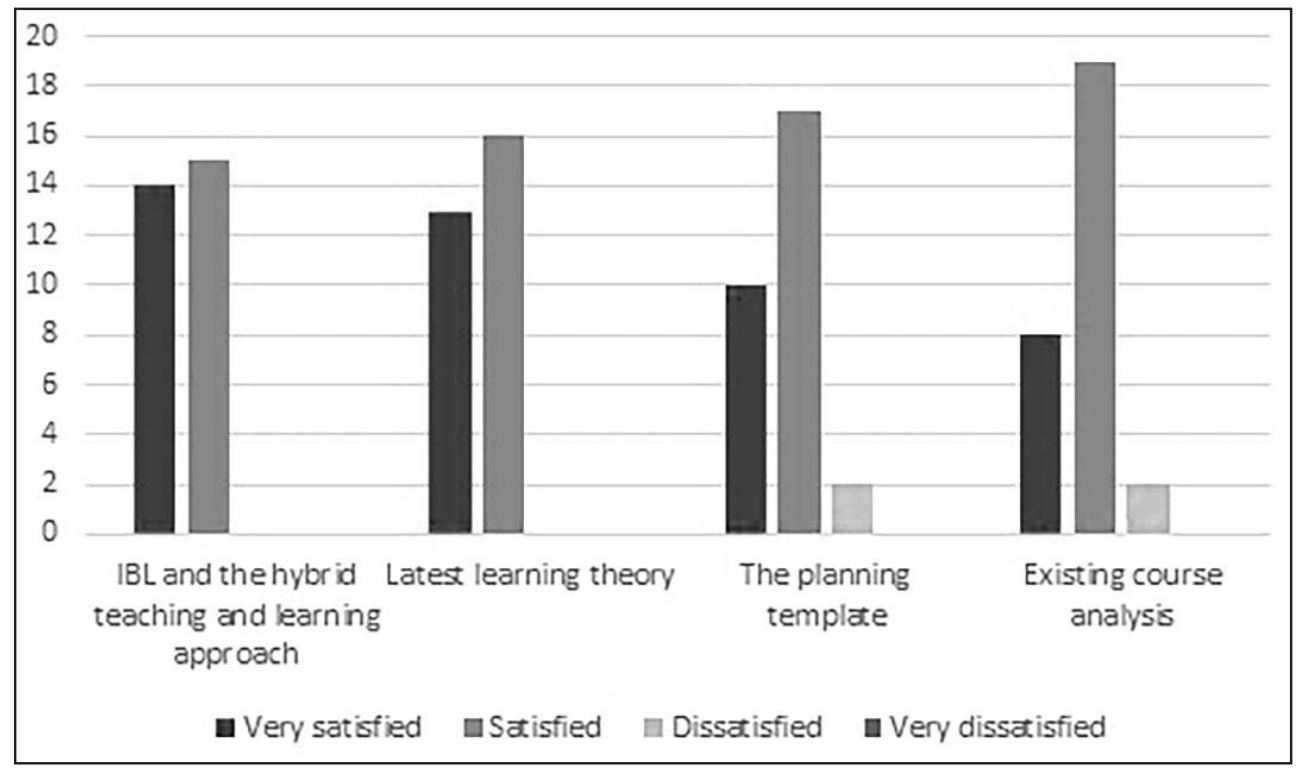

Figure 3: Day 1: Applicability of the topics

It is encouraging that most of the sessions on Day 1 were very well received. This is underscored by a selection of three comments stating what the participants enjoyed: 
The facilitators applied hybrid teaching and learning methods for the workshop, which provided a practical way of approaching hybrid teaching and learning for participants.

I like the group participation and the application during the course of the principles being taught.

Very creative and diverse course materials - good demonstration of how materials can be presented to students.

Suggestions for improvement of Day 1 included, "Time for discussions among participants should be increased to help improve peer-to-peer learning".

\section{Day 2}

The following topics were addressed on Day 2:

- Alternative pedagogies

- Hybrid learning examples in the LMS

- LMS functionalities

- Updating the planning template

On Day 2, the researchers presented sessions on the implications of using hybrid learning, alternative pedagogies and the LMS functionalities. Participants also had the opportunity to update their planning templates. All participants indicated that they were satisfied with the sessions. Although all participants had been using the LMS, it became evident that they were not familiar with all the functionalities and tools the LMS has to offer. One participant commented, "I was amazed as to how I am under-utilizing clickUP". Participants appreciated the time that was made available to plan and develop their courses. Participants could also implement some of the tools and functionalities, as mentioned above. An overwhelming majority $(92 \%)$ was satisfied or very satisfied with the presentation of these topics. Feedback on the applicability of the topics is presented in Figure 4. 


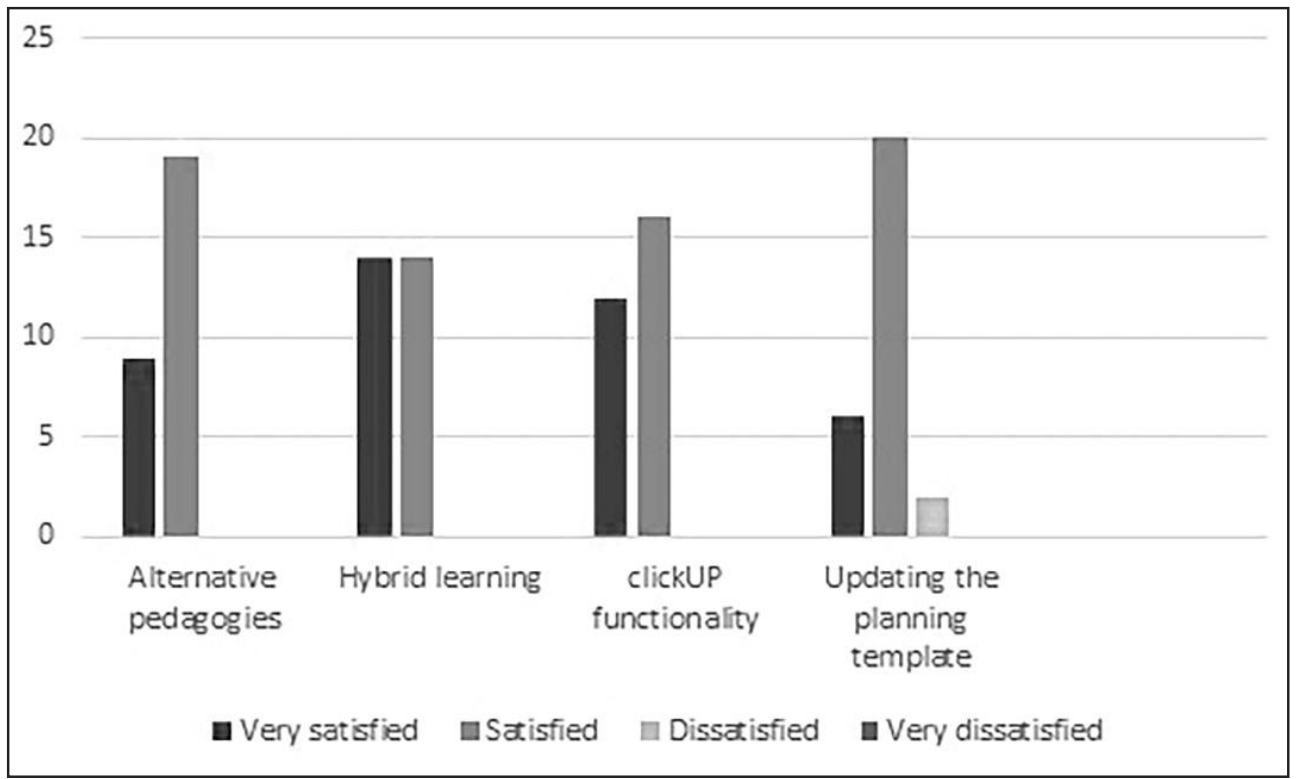

Figure 4: Day 2: Applicability of the topics

The data indicated that most of the participants regarded the sessions as worth their while. Discussions on hybrid learning, the video-conferencing tool in the LMS (Collaborate), alternative pedagogies, badges and new teaching modalities were well received. Some participants expressed the need for dedicated hands-on technical assistance. Since El regularly runs courses that teach the relevant skills, participants should have acquired them before attending the workshop. The opportunity to work on the development of their modules was highly appreciated, and one participant commented, "I enjoy the space to listen to ideas and theories and to apply them immediately". The only negative comment about Day 2 was, "It is a very labour intensive exercise to fully develop a learning pathway!" Participants nevertheless found the topics useful and some requested follow-up workshops.

\section{Day 3}

This day was dedicated to various topics on assessment, including:

- An overview of the basic principles of assessment

- Constructive alignment

- Bloom's taxonomy

- The analysis of a written paper

- Different assessment methods

- The development of an assessment plan

All participants indicated that they found the topics and the presentation worthwhile, as is shown in Figure 5 below. What participants valued most was their critical evaluation of the composition of existing examination papers, using Bloom's taxonomy. A raised awareness of the importance of changing their assessment strategies when using the hybrid teaching model was achieved. As comments from two participants aptly put it, 
This made me realise that my assessment is not up to scratch yet!! But after this it will be better.

I am going to fundamentally change my assessment plan after today's lectures.

Participants joined in the discussions and activities and had to develop an assessment plan during the session - an activity that they found valuable, as the comments show.

I found the practical application of what we have learned, through evaluating and reviewing our own assessment documents, to be very useful and it will help me to be cognizant of key factors I should take into consideration when I develop my assessments.

I now have a better understanding of the importance of incorporating an assessment plan in course/module planning.

The participants likewise found the discussion of their assessment plans with their peers useful, as expressed in the comment, "The discussions with more experienced participants was helpful".

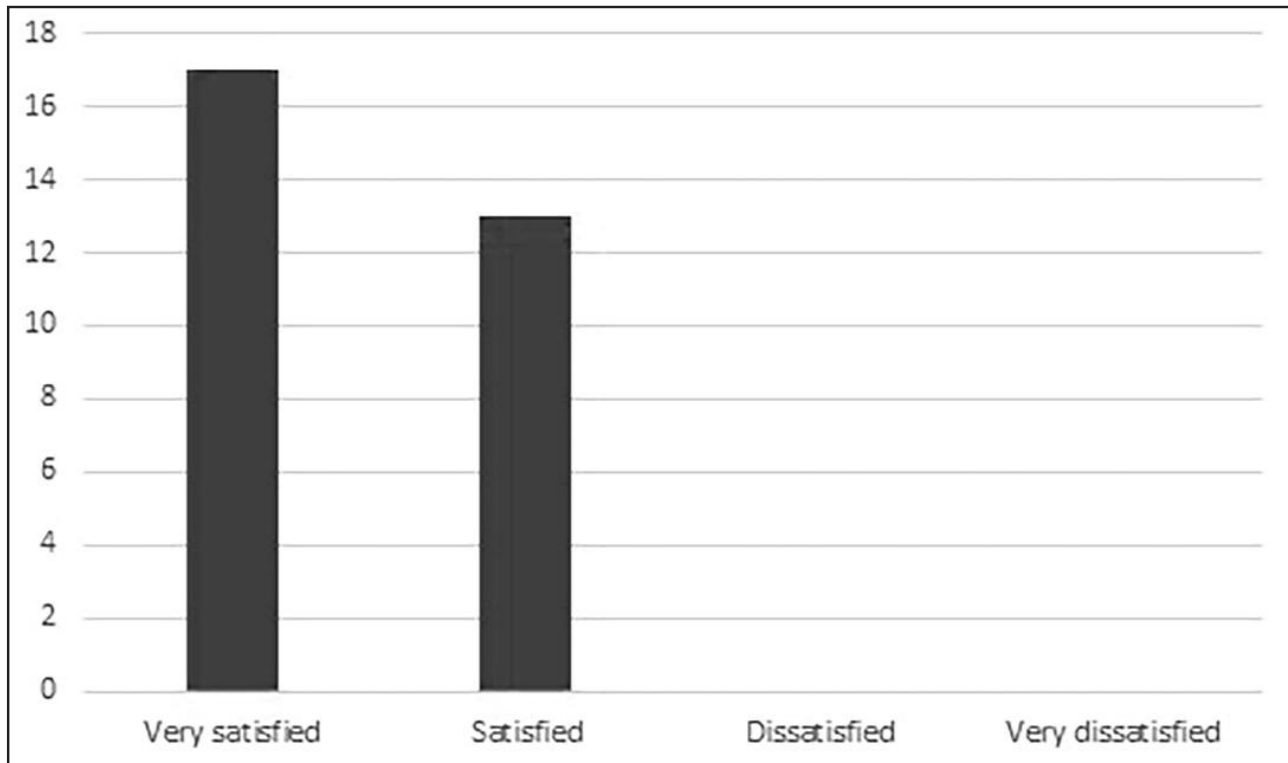

Figure 5: Day 3: Applicability of the topics

\section{Day 4}

Day 4 was dedicated to an introduction to OER and to developing alternative learning resources. The programme focused on:

- Defining OER

- Finding existing OER applicable to veterinary science training

- Analysing the value of OER

- Determining the level of adaptation needed to make the resource appropriate for a veterinary course 
- An investigation into 'Use', 'Re-Use' and 'Remix' strategies

- Creative Commons licensing, and the implications of what each license permits

As depicted in Figure 6 below, only one participant was dissatisfied with the applicability of the session on OER, while $100 \%$ rated the session on creating resources as either applicable or highly applicable. The data denotes that participants were less familiar with OER and that they found the information about OER licensing and searching for OER very practical. One participant expressed the view that "there are many opportunities for contributing to OER as limited open veterinary anatomy resources are available".

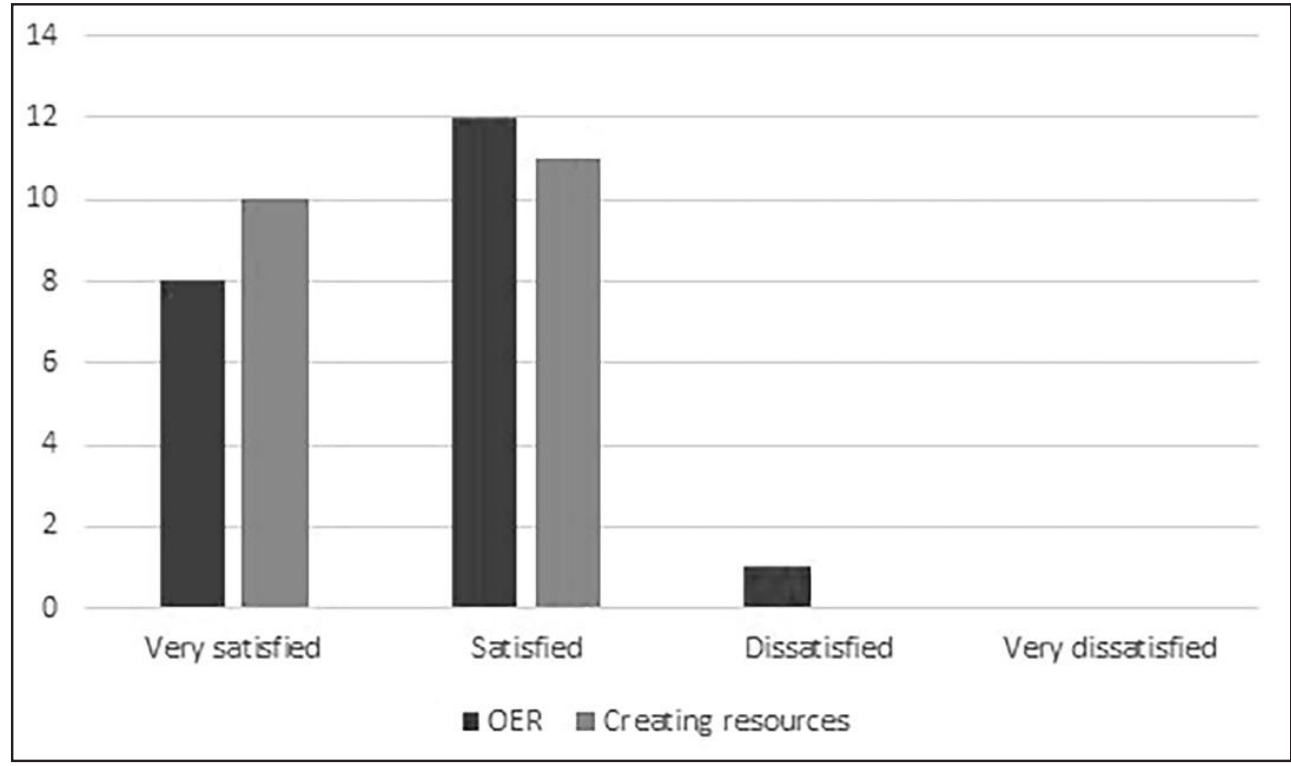

Figure 6: Day 4: Applicability of the topics

The following were positive aspects of the workshop and were well received by the participants:

- exposure to examples and demonstrations of how to develop a variety of digitised resources; and

- the opportunity to apply principles to which they were exposed during the week with some assistance from the researchers.

The opportunity to create their own resources was experienced as highly applicable. One participant indicated that,

creating resources was the highlight of the week, perhaps the best educational session ever.

This was one of the most valuable aspects of the course which was overall extremely interesting and useful.

Suggestions for improvements were mostly about the time available and the fact that it was the last session of the workshop: "I honestly don't feel like being creative at this time of the day and week!" It was suggested that follow-up lunchtime sessions be offered to assist participants 
with applying the tools to which they were exposed during the workshop. Comments from the participants will be taken into consideration when planning future workshops.

\subsection{Post-workshop survey}

The participants were asked (in 2019) to complete a follow-up online survey to determine to what extent they had implemented the training received in the workshop. The instrument is available in Appendix E. Only fourteen of the 37 participants $(38 \%)(n=14)$ completed the survey and the results are depicted in Figure 7.

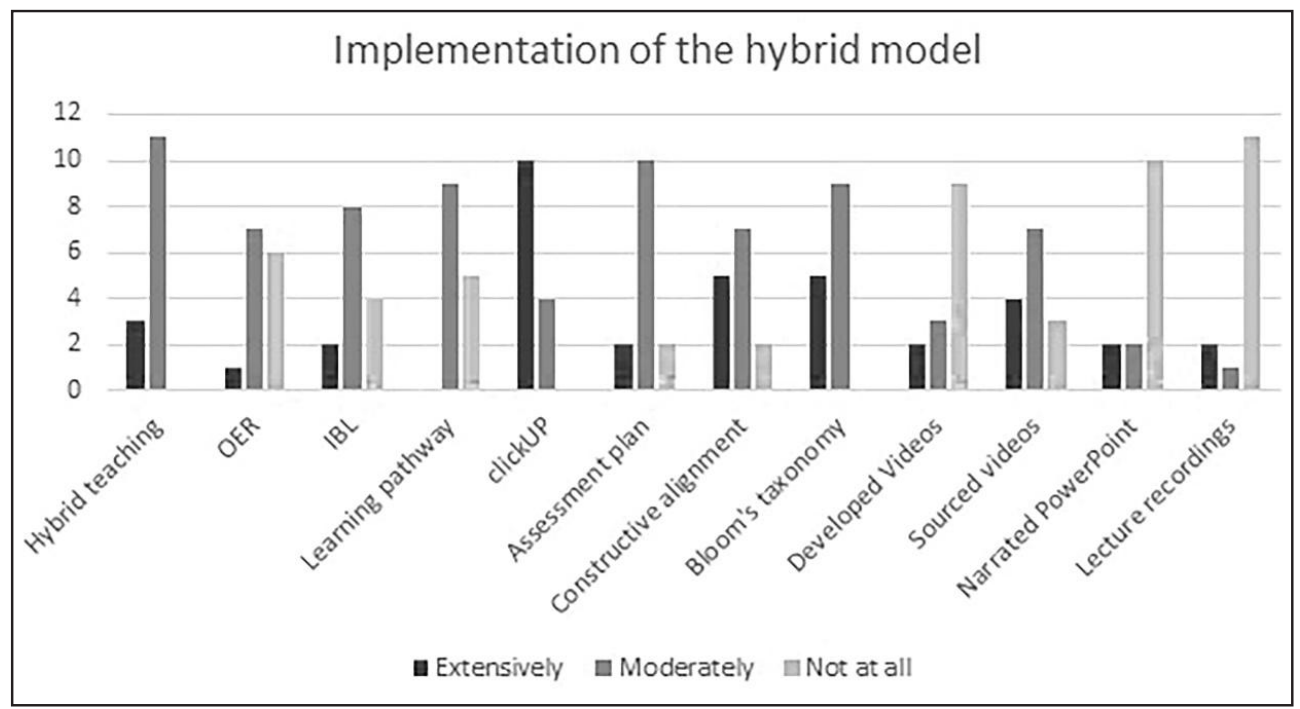

Figure 7: Implementation of the hybrid model

Three participants $(21 \%)$ extensively implemented hybrid teaching while 11 participants (79\%) moderately implemented it. Ten participants (71\%) extensively implemented the LMS and four participants $(29 \%)$ moderately implemented it. All participants implemented Bloom's taxonomy (36\% extensively and $64 \%$ moderately) as part of their teaching practice. Two participants (14\%) did not develop an assessment plan while 10 participants (71\%) moderately implemented an assessment plan.

Participants provided more detail on how they improved their teaching practice after the workshop. The comments below (quoted verbatim) summarise their feedback:

I started with a new module and it was difficult to implement most of the things due to time limitations.

Some of the ideas and skills learned were implemented and further ones will be incorporated as my experience and confidence improves. The course was extremely useful in understanding the students and their needs better.

One needs time to really implement all aspects.

I change my lectures to narrated PowerPoints combined with an enquiry-based and case-based class discussion. Bloom's taxonomy is always kept in mind when developing assessments. 
Teaching in all my modules contains at least $25 \%$ hybrid content - I use clickUP to host videos, formative quizzes and iSpring lectures, use the Module Page function a lot make extensive use of the study guide when setting assessments and planning lectures - construct assessment questions with awareness of the Bloom's level, try to use the mixture of levels appropriate to which year the students are in/ post grad vs undergrad - use iSpring.

Learnt how to get videos from YouTube into clickUP and make it available for the students. Use crossword and word search as revision for students.

I found [T] he [M]ix [M]atters workshop very helpful to construct my module VRP 400 - I just didn't have time to use everything, but I do go back to the MM clickUP page and research what I would to do next!

Awesome workshop!

\subsection{Discussion}

The main aim of the workshop was to provide participants with the skills necessary for implementing the hybrid teaching and learning mode, which implied an active learning, student-centred approach in a hybrid teaching model (cf. Background and objectives). The implementation of such a blended or hybrid model is challenging for lecturers and students (Vaughn, 2007; Warman et al., 2015) (cf. Hybrid teaching and learning in context). The lecturers require support in redesigning their courses to fit this mode of delivery. Addressing this challenge was one of the objectives of the workshop (cf. Background and objectives).

The findings discussed above clearly attest to the success of the workshop. As the workshop was presented, a complete change in attitude was observed, especially from the clinicians. Initially, the participants were quite cynical and sceptical and doubted that the workshop would fulfil all of their needs. Although one participant evaluated the workshop as having been a negative experience, describing it as "going outside my comfort zone", the researchers translate it as a positive comment since it shows that the workshop succeeded in its goal to get lecturers to think differently about their teaching practice. In the end, when the initial scepticism turned into enthusiasm and positive attitudes, the researchers had achieved their goal of bringing about a paradigm shift. As one participant stated, "These four days were extremely stimulating and have encouraged me to get more involved in all the facets of hybrid learning and I am motivated to share with our lecturers and non-believers in our department." The participants realised that the hybrid and flipped classroom modes of delivery provided them with greater flexibility in terms of time and improved learning outcomes (cf. Hybrid teaching and learning in context). Hybrid teaching and learning, and the flipped classroom approach, implied better time management by the lecturers and increased participation in the learning process and engagement by the students. The participants also came to realise that the hybrid model would require that they should continually revisit their teaching methodologies (cf. Hybrid teaching and learning in context).

The researchers believe that despite the concerns about a lack of time, support (cf. Analysis and interpretation of questionnaires - Day 2) and the use of appropriate resources raised by participants (cf. Hybrid teaching and learning in context), the workshop had succeeded in facilitating the acquisition of new and improved teaching and technology skills (cf. Hybrid teaching and learning in context). These skills proved essential for the continuation of teaching activities in the faculty during the lockdown due to COVID-19. Although some concerns about 
the risk associated with delivering a course in a hybrid mode remain, the researchers believe that the knowledge and skills gained by those lecturers who attended the workshop would have - and did - enable them to manage their teaching during and post-COVID-19 well, especially with occasional El support if and when required.

\section{CONCLUSION}

The workshop succeeded in enabling a successful paradigm shift regarding the implementation of hybrid teaching and learning in the faculty. The renewed efforts of faculty management to involve El in training academic staff to pave the way for hybrid learning also proved to be successful (cf. Analysis and interpretation of questionnaires; Discussion). The knowledge gained about hybrid teaching and learning stood the faculty as a whole in good stead when the COVID-19 pandemic caused considerable disruption in the academic offering. The conclusion can therefore be drawn that The Mix Matters workshop was highly significant, because it successfully prepared the faculty's teaching staff to better implement UP's hybrid teaching and learning model. Furthermore, the workshop also prepared the staff to be able to withstand the influence and impact of a pandemic, even though such an event had not been envisaged at the time when the workshop was presented. The researchers wish to encourage and create greater collaboration among academic staff in order to drive hybrid learning in the faculty to uncharted heights in the period beyond COVID-19.

\section{REFERENCES}

Bates, T. 2016. Online learning for beginners: 1. What is online learning? Available at http:// www.tonybates.ca/2016/07/15/online-learning-for-beginners-1-what-is-online-learning/ [Accessed 11 July 2017].

Biggs, J. 2003. Aligning teaching for constructing learning. The Higher Education Academy. Available at https://www.researchgate.net/profile/John_Biggs3/publication/255583992_ Aligning_Teaching_for_Constructing_Learning/links/5406ffe70cf2bba34c1e8153.pdf [Accessed 20 April 2018].

Brown, N., Bower, M., Skalicky, J., Wood, L., Donovan, D., Loch, B., Bloom, W. \& Joshi, N. 2010. A professional development framework for teaching in higher education. In M. Devlin, J. Nagy \& A. Lichtenberg (Eds.). Research and Development in Higher Education: Reshaping Higher Education, 33: 133-143.

Cleveland-Innes, M. \& Wilton, D. 2018. Guide to blended learning. Canada: Athabasca University Commonwealth of Learning.

Creswell, J.W. 2009. Research design: Qualitative, quantitative, and mixed methods approaches, third edition. Thousand Oaks, California: Sage Publications.

Department for Education Innovation. 2019. Taking teaching and learning at UP to the next level. Pretoria: University of Pretoria.

Department for Education Innovation. 2020. Teach \& learn the UP way. Pretoria: University of Pretoria.

Dziuban, C., Moskal, P. \& Hartman, J. 2004. Higher education, blended learning and the generations: Knowledge is power - no more. Available at http://www.oswego.edu/ celt/ Dziuban_Knowledge_is_Power_Oct_2004.doc [Accessed 26 August 2018]. 
Kirkwood, A. \& Price, L. 2016. Technology enabled learning implementation handbook. Available at http://hdl.handle.net/11599/2363 [Accessed 23 October 2018].

Maree, K. \& Pietersen, J. 2007. Surveys and the use of questionnaires. In K Maree (Ed.). First steps in research. Pretoria: Van Schaik.

May, S.A. \& Silva-Fletcher, A. 2015. Scaffolded active learning: Nine pedagogical principles for building a modern veterinary curriculum. Journal of Veterinary Medical Education, 42(4): 332-339. https://doi.org/10.3138/jvme.0415-063R

MicroTek. 2017. What is hybrid learning? How do hybrid and blended learning differ? Available at https://blog.mclabs.com/t-tof-what-is-hybrid-learning [Accessed 21 June 2019].

Mohamedbhai, G. 2020. COVID-19: What consequences for higher education? Available at https://www.universityworldnews.com/post.php?story=20200407064850279 [Accessed 20 October 2020].

National Academies of Sciences, Engineering, and Medicine. 2018. How people learn II: Learners, contexts, and cultures. Washington, DC: The National Academies Press. https:// doi.org/10.17226/24783.

Opinion. 2020. How Covid-19 could change the higher education sector permanently. IOL. Available at https://www.iol.co.za/news/opinion/how-covid-19-could-change-the-highereducation-sector-permanently-438ed3fc-617c-43ab-8fda-d962ee009266 [Accessed 20 October 2020].

Rapanta, C., Botturi, L., Goodyear, P., Guardia, L. \& Koole, M. 2020. Online university teaching during and after the Covid-19 crisis: Refocusing teacher presence and learning activity. Postdigital Science and Education, 2: 923-945. https://doi.org/10.1007/s42438-020-00155-y.

Shenton, A.K. 2004. Strategies for ensuring trustworthiness in qualitative research projects. Education for Information. 22: 63-75. https://doi.org/10.3233/EFI-2004-22201

Steffens, D. \& Reiss, M. 2010. Performance of blended learning in university teaching: Determinants and challenges. Available at https://eleed.campussource.de/archive/6/2627 [Accessed 10 March 2019].

Vaughan, N. 2007. Perspectives on blended learning in higher education. International Journal on E-Learning, 6(1): 81-94.

Vernadakis, N., Antoniou, P., Giannousi, M., Zetou, E. \& Kioumourtzoglou, E. 2011. Comparing hybrid learning with traditional approaches on learning the Microsoft Office PowerPoint 2003 program in tertiary education. Computers \& Education, 56: 188-199. https://doi.org/10.1016/j. compedu.2010.08.007

Warman, S., Pritchard, J. \& Baillie, S. 2015. Faculty development for a new curriculum: Implementing a strategy for veterinary teachers within the wider university context. Journal of Veterinary Medical Education, 42(4): 346-353. https://doi.org/10.3138/jvme.1214-124R1 


\section{APPENDIX A}

\section{MATTERS: DAY 1}

\section{Start of Block: Day 1 Evaluation}

The Mix Matters Workshop: Day 1's evaluation

Instructions for completing the evaluation:

Your feedback on the Mix Matters Workshop is highly valuable to us. Please complete both sections of the evaluation questionnaire at the end of the day.

\section{Section A: Quantitative evaluation}

Indicate your level of satisfaction regarding the applicability of the topics to your discipline:

\begin{tabular}{|l|c|c|c|c|}
\hline & Very satisfied (1) & Satisfied (2) & Dissatisfied (3) & Very dissatisfied (4) \\
\hline Learning Pathway (1) & 0 & 0 & 0 & 0 \\
\hline $\begin{array}{l}\text { IBL and the hybrid } \\
\text { teaching and learning } \\
\text { approach (2) }\end{array}$ & 0 & 0 & 0 & 0 \\
\hline $\begin{array}{l}\text { Latest Learning Theory } \\
\text { (3) }\end{array}$ & 0 & 0 & 0 & 0 \\
\hline $\begin{array}{l}\text { Existing course } \\
\text { analysis (4) }\end{array}$ & 0 & 0 & 0 & 0 \\
\hline $\begin{array}{l}\text { The Planning Template } \\
(5)\end{array}$ & 0 & 0 & 0 & 0 \\
\hline
\end{tabular}

Indicate your level of satisfaction regarding the presentation of the topics below:

\begin{tabular}{|l|c|c|c|c|}
\hline & Very satisfied (1) & Satisfied (2) & Dissatisfied (3) & Very dissatisfied (4) \\
\hline Learning Pathway (1) & 0 & 0 & 0 & 0 \\
\hline $\begin{array}{l}\text { IBL and the hybrid } \\
\text { teaching and learning } \\
\text { approach (2) }\end{array}$ & 0 & 0 & 0 & 0 \\
\hline $\begin{array}{l}\text { Latest Learning Theory } \\
\text { (3) }\end{array}$ & 0 & 0 & 0 & 0 \\
\hline $\begin{array}{l}\text { Existing course analysis } \\
\text { (4) }\end{array}$ & 0 & 0 & 0 & 0 \\
\hline $\begin{array}{l}\text { The Planning Template } \\
(4)\end{array}$ & 0 & 0 & 0 & 0 \\
\hline
\end{tabular}

Section B: Qualitative evaluation:

Comment on any aspects of the sessions using the following guiding prompts:

Positive feedback: 
Negative feedback:

Any suggestions for the improvement of any aspects of the sessions?

\section{END OF BLOCK: DAY 1 EVALUATION}




\section{APPENDIX B}

\section{MATTERS: DAY 2}

\section{Start of Block: Day 2 Evaluation}

The Mix Matters Workshop: Day 2's evaluation

Instructions for completing the evaluation:

Your feedback on the Mix Matters Workshop is highly valuable to us. Please complete both sections of the evaluation questionnaire at the end of the day.

\section{Section A:}

Quantitative evaluation

Indicate your level of satisfaction regarding the applicability of the topics to your discipline:

\begin{tabular}{|l|c|c|c|c|}
\hline & Very satisfied (1) & Satisfied (2) & Dissatisfied (3) & Very dissatisfied (4) \\
\hline $\begin{array}{l}\text { Alternative pedagogies } \\
(1)\end{array}$ & 0 & 0 & 0 & 0 \\
\hline Hybrid learning (2) & 0 & 0 & 0 & 0 \\
\hline clickUP Functionality (3) & 0 & 0 & 0 & 0 \\
\hline $\begin{array}{l}\text { Updating the planning } \\
\text { template (4) }\end{array}$ & 0 & 0 & 0 & 0 \\
\hline
\end{tabular}

Indicate your level of satisfaction regarding the presentation of the topics below:

\begin{tabular}{|l|c|c|c|c|}
\hline & Very satisfied (1) & Satisfied (2) & Dissatisfied (3) & Very dissatisfied (4) \\
\hline $\begin{array}{l}\text { Alternative pedagogies } \\
(1)\end{array}$ & 0 & 0 & 0 & 0 \\
\hline Hybrid learning (2) & 0 & 0 & 0 & 0 \\
\hline clickUP Functionality (3) & 0 & 0 & 0 & 0 \\
\hline $\begin{array}{l}\text { Updating the planning } \\
\text { template (4) }\end{array}$ & 0 & 0 & 0 & 0 \\
\hline
\end{tabular}

\section{Section B:}

Qualitative evaluation: Comment on any aspects of the sessions using the following guiding prompts:

Positive feedback: 
Negative feedback:

Any suggestions for the improvement of any aspects of the sessions?

END OF BLOCK: DAY 2 EVALUATION 


\section{APPENDIX C}

\section{MATTERS: DAY 3}

\section{Start of Block: Day 3 Evaluation}

The Mix Matters Workshop: Day 3's evaluation

Instructions for completing the evaluation:

Your feedback on the Mix Matters Workshop is highly valuable to us. Please complete both sections of the evaluation questionnaire at the end of the day.

\section{Section A: Quantitative evaluation}

Indicate your level of satisfaction regarding the applicability of the topics to your discipline:

\begin{tabular}{|l|c|c|c|c|}
\hline & Very satisfied (1) & Satisfied (2) & Dissatisfied (3) & Very dissatisfied (4) \\
\hline $\begin{array}{l}\text { Assessment (all } \\
\text { sessions) (1) }\end{array}$ & 0 & 0 & 0 & 0 \\
\hline
\end{tabular}

Indicate your level of satisfaction regarding the presentation of the topics below:

\begin{tabular}{|l|c|c|c|c|}
\hline & Very satisfied (1) & Satisfied (2) & Dissatisfied (5) & Very dissatisfied (6) \\
\hline $\begin{array}{l}\text { Assessment (all } \\
\text { sessions) (1) }\end{array}$ & $\mathrm{O}$ & $\mathrm{O}$ & $\mathrm{O}$ & $\mathrm{O}$ \\
\hline
\end{tabular}

Section B: Qualitative evaluation: Comment on any aspects of the sessions using the following guiding prompts:

Positive feedback:

Negative feedback: 
Any suggestions for the improvement of any aspects of the sessions?

\section{End of Block: Day 3 Evaluation}




\section{APPENDIX D}

\section{MATTERS: DAY 4}

\section{Start of Block: Day 4 Evaluation}

The Mix Matters Workshop: Day 4's evaluation

Instructions for completing the evaluation:

Your feedback on the Mix Matters Workshop is highly valuable to us. Please complete both sections of the evaluation questionnaire at the end of the day.

\section{Section A: Quantitative evaluation}

Indicate your level of satisfaction regarding the applicability of the topics to your discipline:

\begin{tabular}{|l|c|c|c|c|}
\hline & Very satisfied (1) & Satisfied (2) & Dissatisfied (3) & Very dissatisfied (4) \\
\hline OER (both sessions) (1) & 0 & 0 & 0 & 0 \\
\hline $\begin{array}{l}\text { Creating resources } \\
\text { (both sessions) (2) }\end{array}$ & 0 & 0 & 0 & 0 \\
\hline
\end{tabular}

Indicate your level of satisfaction regarding the presentation of the topics below:

\begin{tabular}{|l|c|c|c|c|}
\hline & Very satisfied (1) & Satisfied (2) & Dissatisfied (3) & Very dissatisfied (4) \\
\hline $\begin{array}{l}\text { OER (both sessions) } \\
(1)\end{array}$ & 0 & 0 & 0 & 0 \\
\hline $\begin{array}{l}\text { Creating resources } \\
\text { (both sessions) (2) }\end{array}$ & 0 & 0 & 0 & 0 \\
\hline
\end{tabular}

\section{Section B: Qualitative evaluation:}

Comment on any aspects of the sessions using the following guiding prompts:

Positive feedback:

Negative feedback: 
Any suggestions for the improvement of any aspects of the sessions?

End of Block: Day 4 Evaluation 


\section{APPENDIX E}

\section{MATTERS POST-WORKSHOP SURVEY}

\section{Start of Block: Post-workshop Evaluation}

In which year did you attend the Mix Matters workshop?

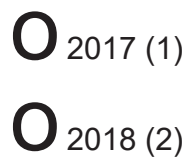

To which extent did you implement any of the following in your teaching practice?

\begin{tabular}{|c|c|c|c|}
\hline & Extensively (1) & Moderately (2) & Not at all (3) \\
\hline Hybrid teaching (1) & 0 & & 0 \\
\hline $\begin{array}{l}\text { Open Education Resources } \\
\text { (2) }\end{array}$ & 0 & & 0 \\
\hline Inquiry-based learning (3) & 0 & & 0 \\
\hline A learning pathway (4) & 0 & & 0 \\
\hline clickUP (5) & ) & & 0 \\
\hline Assessment plan (6) & 0 & & 0 \\
\hline Constructive alignment (7) & & & 0 \\
\hline Bloom's taxonomy (8) & 0 & ) & 0 \\
\hline Developed Videos (9) & 0 & & 0 \\
\hline Sourced videos (10) & ) & & 0 \\
\hline $\begin{array}{l}\text { Narrated PowerPoint } \\
\text { presentations (11) }\end{array}$ & D & & 0 \\
\hline Lecture recordings (12) & 0 & 0 & 0 \\
\hline Other resources (13) & 0 & & 0 \\
\hline
\end{tabular}


Elaborate on your answers provided in Question 2.

Any other comments.

\section{End of Block: Post-workshop Evaluation}

